\title{
Incidence of Hypocalcemia Following Total Thyroidectomy And Its Relation with Age
}

\author{
${ }^{1}$ Basim M, ${ }^{2}$ Abdul Siyad AK \\ ${ }^{1}$ (Senior Resident, Department Of Surgery, Government Medical College, Thrissur,Kerala, India/ \\ ${ }^{2}$ Additional Professor, Department Of Surgery, Government Medical College, Thrissur,Kerala, India)
}

\begin{abstract}
Introduction : Hypocalcemia is the most common complication following Thyroidectomy and hence it should be anticipated and prevented. This study aims at finding the incidence of immediate hypocalcemia following Total Thyroidectomy (TT) and to find its relation with age.

Materials and methods: The aim of this prospective single cohort study was to find the incidence of hypocalcemia in patients who underwent TT in our institution over a period of one year and to study the correlation between age and the incidence of hypocalcemia in these patients. We studied 103 patients. All of them underwent TT for benign Thyroid diseases and were postoperatively followed up for three consecutive days by clinical examination and serum estimation of Calcium to detect hypocalcemia.

Results : Of the 103 patients $86(83.5 \%)$ were females and 17(16.5\%) were males. 57(55.34\%) patients were below 50 years and $46(44.66 \%)$ patients were above 50. Among sample population, 25 (24.27\%) developed hypocalcemia with a serum calcium level less than $8 \mathrm{mg} / \mathrm{dl}$ which is in accordance with the reference standard .In less than 50 year age group, 12 out of 57 (21.05\%) developed hypocalcemia while in more than 50 age group, $13(28.26 \%)$ had hypocalcemia.
\end{abstract}

Conclusions : We could detect hypocalcemia in a significant number of patients and patients above 50 yrs were at higher risk for the same though the observation was statistically not significant.

Keywords: Total Thyroidectomy, Hypocalcemia, Age.

\section{Introduction}

Total Thyroidectomy (TT) is now the procedure of choice for benign multinodular goiter. TT reduces the need for re-exploration and postoperative hormonal administration is also easy. Complications of thyroidectomy include bleeding, hematoma formation, hypocalcemia, recurrent laryngeal nerve palsy etc. Hypocalcemia is observed in up to one third to half of total or completion Thyroidectomy patients and is the most common complication. Though majority are transient, it is a troublesome complication and it continues to challenge even experienced surgeons. Hypocalcemia leads to prolonged hospital stay and increases the need for biochemical tests. The development of hypocalcemia after TT are multifactorial and some of these factors include surgical trauma to the parathyroid glands, incidental parathyroidectomy, extent of surgery, experience of the surgeon, hyperthyroidism, stress induced urinary loss of calcium, retrosternal goitre, thyroid carcinoma etc. Various surgical techniques have evolved to preserve parathyroid function. However,transient hypoparathy roidism still occurs in around $30 \%$ of patients owing to parathyroid manipulation, devascularisation etc Permanent hypoparathyroidism is less than $5 \%$ in majority of surgical units. Following thyroidectomy bleeding or hematoma formation are closely watched for during initial 24 hours. Since then the main discharge-limiting factor is development of hypocalcaemia and patients who are not at risk of hypocalcaemia may be discharged on day 1 following surgery. Symptoms of hypocalcemia are neuromuscular and occasionally psychotic episodes Since hypocalcemia is the major discharge limiting factor, need for shorter hospital stay has urged many studies to identify risk factors for post Thyroidectomy hypocalcemia and various measures to reduce its incidence. This study also aims at the same.

\section{Aims And Objectives}

1.To study the incidence of hypocalcemia in patients who underwent TT.

2.To study the correlation between hypocalcemia and age in patients following TT.

\section{Materials And Methods}

3.1Study design and setting : This was a Prospective study (single cohort). This was done in the Outpatient department, and surgical wards of Govt. medical college, Thrissur. We studied patients for one year from 2014 Aug to 2015Aug.

3.1 Study participants : Patients undergoing TT in medical college hospital, Thrissur, under General Surgery Department, who are willing to participate in the study. 
3.2 Inclusion criteria : Males and females with age 18 years and above who underwent TT.

3.4 Exclusion criteria : Patients with carcinoma thyroid and Patients with other medical illness which may affect serum calcium level like chronic renal failure.

3.5 Sample size : All consecutive cases of "TT above 18 years" presenting to Thrissur medical college. \& sample size was calculated using

$$
\mathrm{N}=(\mathrm{Z} \alpha)^{2} \mathrm{p} \mathrm{q} / \mathrm{d}^{2}
$$

[ A meta analysis ${ }^{(\mathbf{1 0})}$ showed $50 \%$ of transient hypocalcemia following total thyroidectomy, providing a minimum sample size of $\underline{\mathbf{9 6}}$ by above equation taking prevalence as 50\%]

\subsection{Study tool:}

- Proforma: interviewer administered, pre-tested, semi structured questionnaire was prepared.

- Informed consent was obtained.

- Measurements: Routine clinical examination with special attention to signs of hypocalcemia followed by serum calcium estimation in each case.

\subsection{Methodology:}

The study was conducted in Govt. medical college, Thrissur among patients aged more than 18 years who were posted for TT for benign disorders of thyroid. After getting informed consent from the patient ,history was taken according to pretested semi structured questionnaire provided, with routine clinical examination followed by necessary routine laboratory investigations and imaging studies. Following surgery patients were followed up in ward for 3 days. Patients were evaluated for clinical signs of hypocalcemia as well as with serum calcium levels. Clinical symptoms like Circum oral numbness, Paresthesia. and signs like carpopedal spasm ,Chvostek's sign positivity are taken as positive clinical hypocalcemia.

The clinical manifestations were analysed but a serum calcium level of less than $8 \mathrm{mg} / \mathrm{dl}$ was taken as laboratory hypocalcemia. Values were obtained on three consecutive days following surgery and a single observation of less than $8 \mathrm{mg} / \mathrm{dl}$ was considered as hypocalcemia. Patients with laboratory hypocalcemia were given oral calcium and vitamin D3. Patients who developed symptomatic hypocalcemia were given iv calcium gluconate. Data was analyzed to find out the incidence of hypocalcemia and incidence in elderly patients $(>50$ year) was compared to that of young patients ( $<50$ years $)$.

\subsection{Data analysis :}

Data collected from each individual was entered to excel worksheet after coding of variables \&analysis was done with appropriate statistical software like epi info (version 7). Qualitative data was analyzed with incidence, chi- square test, multilogistic regression analysis and data was depicted with pie charts, bar diagrams $\&$ appropriate methods. Quantitative data was analyzed using mean, standard deviation \& appropriate statistical test of significance.

\section{1: Sex Distribution.}

\section{Results}

Table 1

\begin{tabular}{|c|c|c|}
\hline Sex & Frequency & Percent \\
\hline $\mathrm{F}$ & 86 & $83.5 \%$ \\
\hline $\mathrm{M}$ & 17 & $16.5 \%$ \\
\hline Total & 103 & $100 \%$ \\
\hline
\end{tabular}

\section{2: Age Distribution}

Table 2

\begin{tabular}{|c|c|c|}
\hline Age & Frequency & Percent \\
\hline$<50$ & 57 & $55.34 \%$ \\
\hline$>50$ & 46 & $44.66 \%$ \\
\hline Total & $\mathbf{1 0 3}$ & $\mathbf{1 0 0 . 0 0 \%}$ \\
\hline
\end{tabular}

\section{3 : Incidence Of Hypocalcemia.}

\begin{tabular}{|c|c|c|}
\hline Hypocalcemia & Frequency & Percent \\
\hline N & 78 & $75.73 \%$ \\
\hline Y & 25 & $24.27 \%$ \\
\hline Total & $\mathbf{1 0 3}$ & $\mathbf{1 0 0 . 0 0 \%}$ \\
\hline
\end{tabular}




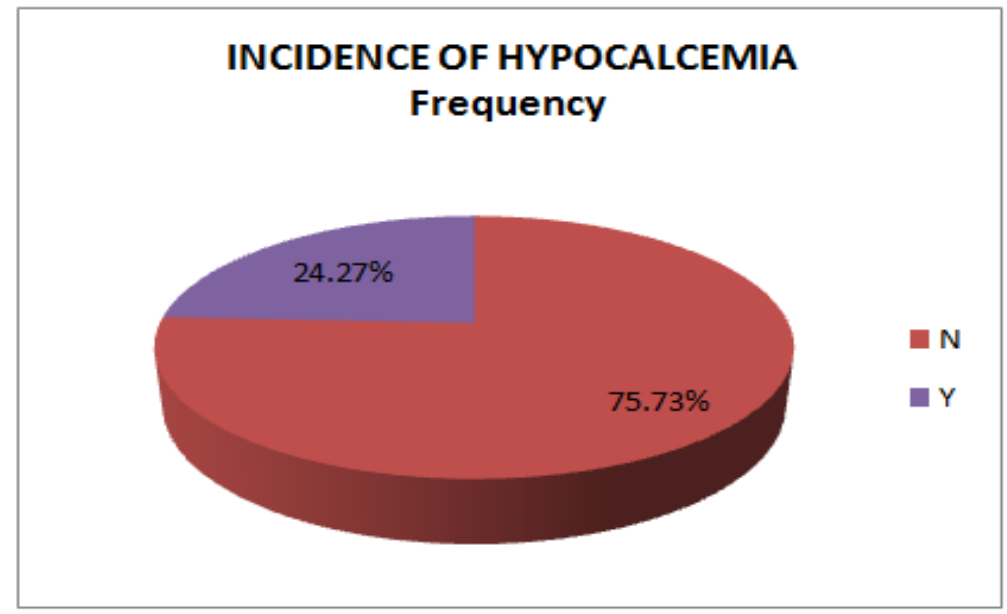

4.4: Incidence Of Chvostek's Sign

\begin{tabular}{|c|c|c|}
\hline Chvostek's sign & Frequency & Percent \\
\hline $\mathrm{N}$ & 78 & $75.73 \%$ \\
\hline Y & 25 & $24.27 \%$ \\
\hline TOTAL & $\mathbf{1 0 3}$ & $\mathbf{1 0 0 . 0 0 \%}$ \\
\hline
\end{tabular}

4.5: Incidence Of Carpopedal Spasm

\begin{tabular}{|c|c|c|}
\hline Carpopedal Spasm & Frequency & Percent \\
$\mathrm{N}$ & 95 & $92.23 \%$ \\
\hline $\mathrm{Y}$ & 8 & $7.77 \%$ \\
\hline Total & $\mathbf{1 0 3}$ & $\mathbf{1 0 0 . 0 0 \%}$ \\
\hline
\end{tabular}

4.6: Age Related Incidence Of Hypocalcemia Table 6.a AGE_RECORDED $=<50$

\begin{tabular}{|c|c|c|}
\hline Hypocalcemia & Frequency & Percent \\
\hline $\mathrm{N}$ & 45 & $78.95 \%$ \\
\hline $\mathrm{Y}$ & 12 & $21.05 \%$ \\
\hline Total & $\mathbf{5 7}$ & $\mathbf{1 0 0 . 0 0 \%}$ \\
\hline
\end{tabular}

Table 6.b AGE_RECORDED $=>50$

\begin{tabular}{|c|c|c|}
\hline HYPOCALCEMIA & Frequency & Percent \\
\hline $\mathrm{N}$ & 33 & $71.74 \%$ \\
\hline Y & 13 & $28.26 \%$ \\
\hline TOTAL & $\mathbf{4 6}$ & $\mathbf{1 0 0 . 0 0 \%}$ \\
\hline
\end{tabular}

Chart .2 Age Related Incidence Of Hypocalcemia

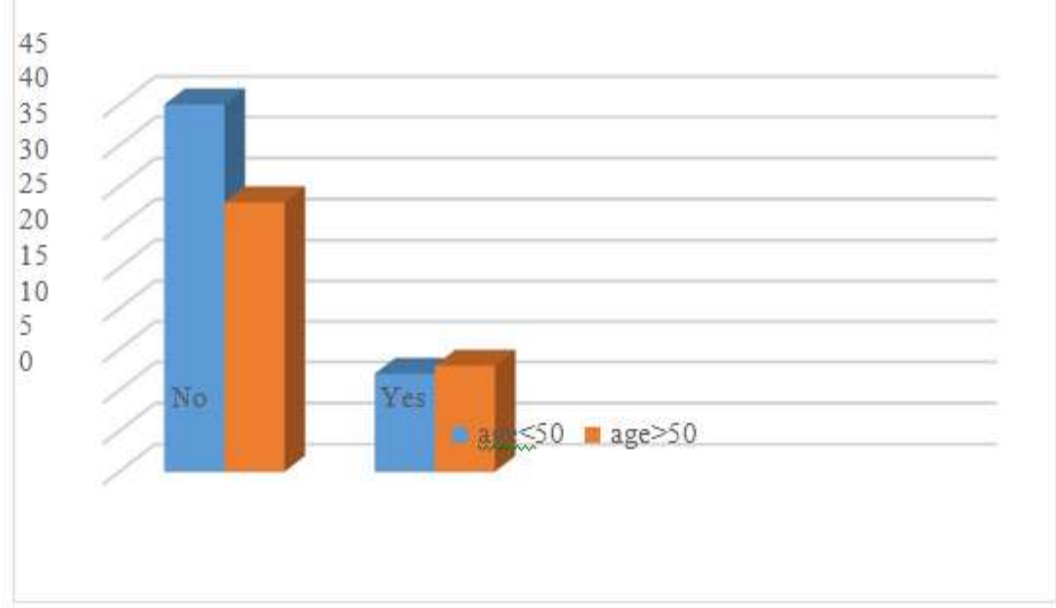




\section{7: Relation between Age and hypocalcemia}

Table .7

\begin{tabular}{|c|c|c|c|}
\hline & \multicolumn{2}{|c|}{ Hypocalcemia } & \\
\hline AGE & $\mathbf{Y}$ & $\mathbf{N}$ & Total \\
\hline$>50$ & 13 & 33 & 46 \\
\hline$<50$ & 12 & 45 & 57 \\
\hline Total & 25 & 78 & 103 \\
\hline
\end{tabular}

Odds ratio 1.47 ( $95 \%$ CI 0.6- 3.5)

\section{Discussion}

Hypocalcemia is the most common metabolic complication following thyroidectomy ${ }^{1}$. The incidence varies in various studies. Transient hypocalcemia that occurs immediately after surgery usually manifests around second postoperative day but can be as early as first postoperative day. The cause is attributed to parathyroid gland ischemia due to gland manipulation, vasospasm and venous engorgement. Permanent hypocalcemia occurs due to removal of parathyroid glands. Incidence of transient hypocalcemia varies from 5\% to $60 \%$ in various studies and that of permanent hypocalcemia is around $1.5 \%$ to $5 \% \%^{2,3,4,5,6}$. Visual identification and preservation of at least 2 parathyroid glands reduces the incidence of hypocalcemia ${ }^{8}$. A marked fall in serum calcium on first postoperative day is a reliable predictor of imminent hypocalcemia ${ }^{9}$. In our study out of 103 patients studied who underwent TT, 86(83.5\%) were females and 17(16.5\%) were males. Most of Thyroid diseases are more seen in women.

Sir Richard Owen made the original description of post Thyroidectomy hypocalcemia in 1850. Tetany was described in 1879 in a patient who underwent thyroidectomy (and incidental parathyroidectomy), and the connection between the parathyroids and tetany was identified in 1891. Post thyroidectomy hypocalcemia can be transient or permanent. Transient hypocalcemia is far more frequent than permanent. While permanent hypocalcemia is because of removal of parathyroid glands, transient hypocalcemia is mainly due to parathyroid gland ischemia. Post thyroidectomy hypocalcemia manifests on second to fifth postoperative day but can be delayed upto 2-3 weeks ${ }^{12}$. Earliest symptoms of hypocalcemia include circum oral numbness and acral paraesthesia. Later carpopedal spasm and laryngospasm may develop depending on severity of disease. Other symptoms of hypocalcemia include, Neuromuscular symptoms like, ${ }^{13}$ perioral numbness muscle cramps which; may progress to carpopedal spasm and airway obstruction. Neurologic symptoms like irritability, fatigue and seizures may also be found. Clinical signs include a positive Chvostek's sign and positive Trousseau's sign. Around $25 \%$ of normal individuals with normal calcium level have positive chvostek's sign. To elicit Trousseau sign, the sphygmomanometer cuff is inflated above the systolic blood pressure for 3 minutes. Trousseau sign is more specific than Chvostek's sign. A positive Trousseau sign is seen in $1 \%-4 \%$ of healthy people ${ }^{15}$. Both these signs are due to increased neuromuscular irritability because of hypocalcemia.

In our observation 21 out of 103 patients (20.39\%) developed circum oral numbness. We found among sample population, 25(24.27\%) had Chovstek's sign positivity. 8 patients studied $(7.77 \%)$ experienced carpopedal spasm. Eventhough we studied the clinical signs we regarded hpocalcemia as serum values less than $8 \mathrm{mgm} / \mathrm{dl}$. Among sample population, 25 (24.27\%) developed hypocalcemia with a serum calcium level less than $8 \mathrm{mg} / \mathrm{dl}$. which is in accordance with the reference standard. Patients were categorized into less than 50 and more than 50 age group. 57(55.34\%) patients were below 50 years and 46(44.66\%) patients were above 50.Different studies have concluded differently on the influence of age on incidence of post thyroidectomy hypocalcemia. Some have found age as a risk factor whereas some others have found no difference in incidence with age ${ }^{16,17}$

We observed that in less than 50 year age group, 12 out of 57 (21.05\%) developed hypocalcemia while in more than 50 age group, 13 out of $46(28.26 \%)$ had hypocalcemia. A correlation between age and the incidence of post Thyroidectomy hypocalcemia was studied which showed an odds ratio of 1.47 (95\% CI 0.63.5 ) with a $\mathrm{p}$ value of 0.39 . Eventhough the observation had clinical relevance statistically it was found to be insignificant. The exact reason for relation between age and increased risk of hypocalcemia is not clear. Vitamin $\mathrm{D}$ has a critical role in calcium homeostasis. Advanced age is reported to be a risk factor for vitamin D deficiency. This is because of age related decline in renal 1-alpha hydroxylase activity and decreased intestinal absorption of calcium combined with decline in cutaneous accumulation of 7 - dehydrocholesterol which is converted to previtamin D3 by solar UV light. Postoperative administration of oral calcium and vitamin D3 has found to reduce the incidence of postoperative hypocalcemia ${ }^{7}{ }^{18}$. In this study we observe a statistically insignificant correlation between age and chance for hypocacemia.

\section{Conclusion}

Incidence of hypocalcemia among sample population was $24 \%$. The risk of postoperative hypocalcemia was more in patients aged more than or equal to 50 years with more than 50 age group having 
1.47 times higher risk of developing hypocalcemia which was however found to be statistically not significant.

Abbreviations TT - Total Thyroidectomy.

\section{References}

[1]. Predictors of hypocalcemia after total/near total thyroidectomy. Kara M, Telloglu G, Krand O, Fersahoglu T, Berber I, Erdogdu E, Ozel L, Titiz MI. Surg today. 2009; 39(9): 752-7. PMID 19779770.

[2]. Metabolic complications of thyroid surgery Hypocalcemia and hypothyroidism, hypocalcitonemia and hypothyroidism and hyperthyroidism. Falk SA Thyroid diseases $2^{\text {nd }}$ edition. New York.

[3]. Complications of thyroid surgery, How to avoid them and observation on their possible effect on whole patient. Reeve T, Thomson NW, World J Surg 2000;

[4]. Parathyroid function in early post operative period after thyroidectomy. Lemaire FX, Debruyne F, Delare P. Acta otorhinolaryngol Belg. 2001;55(5) 187-97. PMID 11441478.

[5]. Parathyroid preservation during total thyroidectomy. Saha AR, Jeffe BM. Am J Otolaryngol 1998;19(2);113-7. PMID 9550443.

[6]. Hypocalcemia after thyroidectomy: Demester Mirkin N, Hoogh L, Von Geerstruyden, Martelaer V. Arch Surg. 1992 Jul; $127(7)$ : 854-8.

[7]. Thyroidectomy and parathyroids. Michie W, stowers JM, Frazer SC, Gunn A. British J. surg. 1965; 52: 503-14. PMID 14315689.

[8]. Surgical treatment of substernal goiter analysis of 59 cases. Agha A, Glockzin G, Ghali N. Surgery today 2008; 85: 29-43.

[9]. Identification of patients at high risk for hypocalcemia after total thyroidectomy. Tredisi P, Grosso E, Tradati N, Gibelli B. Acta Otorhinolaryngol. Ital. 2011Jan- 31(3); 144-48.

[10]. Owen R: On the anatomy of the Indian rhinoceros (Rh. unicornis,L). Tran Zool Soc Lond 4:31-58, 1862.

[11]. Gley ME: Sur les functions du corps thyroide. CR Soc Biol 43:841-843, 1891

[12]. Bailey and love short practice of surgery; $26^{\text {th }}$ ed. P762.

[13]. Kaye M, Somerville PJ, Lowe G, Ketis M, Schneider W. Hypocalcemic tetany and metabolic alkalosis in a dialysis patient: an unusual event. Am J Kidney Dis. 1997 Sep. 30(3):440-4.

[14]. 14.Eraut D. Idiopathic hypoparathyroidism presenting as dementia. Br Med J. 1974 Mar 9. 1(5905):429-30.

[15]. Shoback D, Marcus R, Bikle DMetabolic bone disease. GreenspanFS, Gardner DG, editors. Basic and clinical endocrinology. 3rd ed. Los Altos (CA): Lange Medical Publications; 2004. p. 324.

[16]. The impact of age and oral calcium\& vit D supplementation on post operative hypocalcemia after total thyroidectomy- A prospective study. Tolone S, Roberto R, del Genio G, Parmeggani D, Brusciano L, Casalino G, Bosco A, D’Alessandro A, Pirozzi R, Rossetti G et al. BMC Surg. 2013;13 suppl. 2 PMID 24267491.

[17]. Hypocalcemia following total thyroidectomy: An analysis of 806 patients. Nair CG, Babu MJ, Menon R, Jacob P. Indian J. Endocrinol Metab. 2013 Mar; 17(2): 298/303. PMID 23776907.

[18]. Thyroid surgery in geriatric patients- A literature review. Gervasi R, Orlando G, Amato B, Docimo G, Zeppa P, Puzziello A. BMC Surg. 2012: 12 suppl. PMID 23173919.

\section{Ethical concern:}

- The study protocol was submitted to Ethics Committee (IRC) of Govt. Medical College, Thrissur for approval and study was conducted after obtaining the approval.

- A written informed consent was taken from the participants.

- The information collected was used only for the purpose of study and strict confidentiality was maintained throughout the study.

Budget for the study: Expenses for the study was handled by the investigator. No other source of funds available. No economic burden was there on the patient. Estimated budget include that of paper works.

\section{Conflict of interest}

The authors declare that they have no conflicts of interest. 